\title{
Renal Neoplasm During Pregnancy: A Single Center Experience
}

\author{
Brecht Chys, ${ }^{1}$ Sander Dumont, ${ }^{2}$ Kristel Van Calsteren, ${ }^{2}$ Maarten Albersen, ${ }^{1}$ \\ Steven Joniau ${ }^{1}$
}

\section{Clinical Practice Points}

- Renal neoplasms in pregnancy are a rare entity, benign as well as malignant. They confront the clinician with an uncomfortable and unfamiliar dilemma. There is no clarity about the ideal treatment approach and time frame for surgery during pregnancy.

- Using a retrospective chart review of our own clinical database (1994-2017), we present a cohort of 9 women with a newly diagnosed renal neoplasm during or within the first month after pregnancy.

- Three patients presented a benign neoplasm and 6 showed a malignant renal cell carcinoma.

- Our results illustrate an unprecedented higher prevalence of atypical and syndromic renal tumors because half of the cohort with malignancy presented with a chromophobic type.
- Tuberous sclerosis complex was present in 2 cases of the cohort with benign neoplasm. The favored surgical technique was partial nephrectomy (44\%), followed by radical nephrectomy (33\%).

- To our knowledge, no case series of this magnitude has been reported. The unprecedented inclusion of benign neoplasm implies a scope beyond malignancy, tackling the diagnostic dilemma of an incidental renal mass in pregnancy.

- These diagnostic and therapeutic challenges are discussed, and trimester-determined solutions are elaborated. A low threshold for attribution of symptoms to nonobstetric etiologies should be used in pregnant patients.

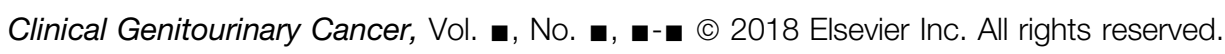

Keywords: Gestation, Obstetrics, Renal cell carcinoma, Surgery, Urology

\section{Introduction}

Renal masses are categorized into benign neoplasms, like angiomyolipoma, and malignant neoplasms, such as renal cell carcinoma (RCC). Renal malignancies make up $2 \%$ to $3 \%$ of all adult cancers and occur predominantly in the fifth and sixth decade. ${ }^{1}$ In general, the incidence of malignancies during pregnancy is estimated at approximately 1:1000 pregnancies. $^{2}$ Most prevalent tumors during pregnancy are breast cancer, cervical cancer, melanoma, and hematological malignancies. ${ }^{2}$

Although renal masses during pregnancy form an extraordinary rare entity, they remain severely under-reported. To our knowledge, only 111 cases of RCC during pregnancy have been described to

B.C. and S.D. contributed equally to this work.

${ }^{1}$ Department of Urology

${ }^{2}$ Department of Gynecology and Obstetrics, University Hospitals Leuven, Belgium

Submitted: Feb 4, 2018; Accepted: Feb 20, 2018

Address for correspondence: Steven Joniau, MD, PhD, Department of Urology, University Hospitals Leuven, Herestraat 49, 3000 Leuven, Belgium E-mail contact: steven.joniau@uzleuven.be date. ${ }^{1,3-8}$ In this report, we present a case series of 9 patients with a newly diagnosed renal neoplasms in pregnancy or within the first month postpartum. To our knowledge, no case series of this magnitude has been reported. The unprecedented inclusion of benign neoplasm implies that this study aims beyond the scope of malignancy, tackling the diagnostic dilemma of incidental renal mass detection in pregnant patients.

Improved imaging and increasing maternal age could explain a steadily rising incidence of malignant renal neoplasms, corresponding with a general rising trend of malignancies during pregnancy. ${ }^{1,9}$ Unfortunately, inadequate population size limits publication of evidence-based guidelines, implying a strong variability in clinical management. Although many difficulties have been described, an overview of gestational age (GA)-specific challenges is desirable. Using our compiled cases we examine the applicability of generally accepted recommendations.

\section{Methods}

Our centralized patient database (1994-2017) was queried in September and November 2017. The search query used was: (nephrectomy and pregnant) or (RCC and pregnant) or (kidney and 


\section{Renal Neoplasm During Pregnancy: A Single Center Experience}

mass and pregnant). An additional search query was performed: (AML or angiomyolipoma) and (pregnant or pregnancy). All terms were in entered in Dutch.

Patient records were manually screened, and we marked all records of patients with renal neoplasms and all with a renal neoplasm during pregnancy or within the first month after delivery.

From our initial data set of 191 patients, we excluded all male patients, those with Wilms tumors, and neoplasms not associated with pregnancy. One patient was excluded because of suspected relapsing RCC, who showed newly developed liver metastasis during pregnancy, 11 months after primary diagnosis.

All patients with a diagnosis of a renal neoplasm during pregnancy or within the first month postpartum were included in our final selection of patients.

This report was approved by the ethical commission of the University Hospitals of Leuven.

\section{Results}

A database of 191 unique patients was retrieved (Figure 1). All files of the female patients $(n=177)$ were reviewed. Patients with any kind of renal neoplasm were included.

In our final selection, 6 unique patients were diagnosed with a pregnancy-associated RCC whereas 3 patients had a diagnosis of a benign renal neoplasm. One additional patient had a progressive RCC during pregnancy. An overview of patient data is provided in Table 1.

The mean GA at diagnosis was 21 weeks 4 days. Nearly all patients consulted because of pain, most frequently in the lumbar region but also in the hypochondriac area. One patient was faced with an accidental finding in the diagnostic workup of hypertension and declining renal function. Everyone was initially examined with abdominal ultrasound imaging, followed by magnetic resonance imaging (MRI) in all but one. Other means of imaging like a computed tomography (CT) scan were reserved until after delivery.

All malignant renal neoplasms were diagnosed as RCC. Half of them were identified as clear-cell carcinoma, the remainder were chromophobic. The mean Fuhrman grade and Leibovich scores were 2 and 4, respectively. A mean diameter of $11.1 \mathrm{~cm}$ was noted.

The most favored surgical treatment in this cohort was partial nephrectomy (4 of 9), followed by radical nephrectomy (3 of 9). Only 1 patient received radiofrequency ablation as treatment. Adjuvant therapy was indicated in 1 case only.

Of the 6 pregnancies that reached third trimester, 3 women $(50 \%)$ delivered via a spontaneous vaginal delivery, 1 (17\%) was delivered through an elective cesarean section, and 2 pregnancies (33\%) were prematurely induced. Termination of pregnancy (TOP) was noted twice: the first because of a spontaneous abortion in the first trimester and the second because of voluntarily opting for TOP. Except for 1 child born with tuberous sclerosis, all newborns were healthy and lacking significant morbidities related to the maternal antecedents or interventions.

\section{Discussion}

\section{Clinical Presentation}

The diagnosis of renal neoplasms during pregnancy is a challenging one. Renal masses remain asymptomatic in early stages of disease. ${ }^{4}$ If clinical symptoms arise, tumors are more likely to be voluminous. In our series, most patients had a substantial tumor. All but 1 patient presented with abdominal pain.

Typical symptoms of renal neoplasms are hematuria, fever, unexplained weight loss, fatigue, and a palpable abdominal mass, but also hypertension and decreasing glomerular function due to renal vessel compression, as well as lumbar region pain. Many of these are common pregnancy-related complaints, making the diagnosis during pregnancy even more difficult. Furthermore, palpation of abdominal masses in pregnant patients is less straightforward.

\section{Diagnostic Workup}

Most findings of renal neoplasms during pregnancy are accidental. Although transabdominal obstetric ultrasound examinations are routinely performed during pregnancy, kidneys are not assessed by default. Because of fetal radiation exposure, abdominal CT imaging should be avoided. MRI is thus the preferred method for detailed radiographic examination. ${ }^{10,11}$ In our case series all but 1 patient with a renal mass suspected on ultrasound imaging, received a supplementary MRI evaluation.

There is some controversy concerning the safety of gadolinium, an intravenous contrast for MRI examination. Current guidelines allow a very restrictive use of gadolinium in pregnant patients if renal function is adequate. ${ }^{1,12}$

A selection of MRI images of these patients around the time of diagnosis is shown in Figure 2.

Preoperative histological evaluation using core needle biopsy (CNB) or fine-needle aspiration (FNA) is strikingly little discussed in literature. Most authors conclude that imaging studies are sufficient for diagnosis. ${ }^{1}$ Selected patients who present small, ambiguous tumors are potential candidates for CNB or FNA. Arguments against percutaneous biopsy are seeding of the tumor and intralesional bleeding, although this is very rare and of little clinical significance. ${ }^{11}$ In our opinion, preoperative histological evaluation could significantly add to a correct diagnosis and aid to therapeutic decision-making. Unfortunately, negative biopsies have a low negative predictive value of $68.5 \% .{ }^{13}$ Moreover, the histology of a biopsy is known to vary dramatically compared with the final resection specimen. ${ }^{13}$ Because all of our patients were adamant to undergo immediate active treatment and were considered excellent surgical candidates, uncertain biopsies had little to no value. However, if a pregnant patient is in doubt to undergo surgery and biopsies cannot prove malignancy, postponing intervention until after delivery is more arguable because fetal risk will be reduced without compromising maternal outcome.

\section{Pathophysiology}

Risk factors in the development of kidney cancer are smoking, obesity, family history, age, hypertension, treatment for kidney failure, and certain inherited syndromes like tuberous sclerosis complex (TSC).

Multiple pathophysiological hypotheses have been suggested concerning RCC in pregnancy. The hormone hypothesis, which is on the basis of 4 pillars, is considered the most dominant theory. First, estrogen levels are known to peak during pregnancy. Second, normal as well as RCC cells express estrogen receptors. ${ }^{3}$ The induction of RCC in laboratory mice using estrogen is a third argument. ${ }^{1}$ Finally, (multi)parity is an established risk factor in the 


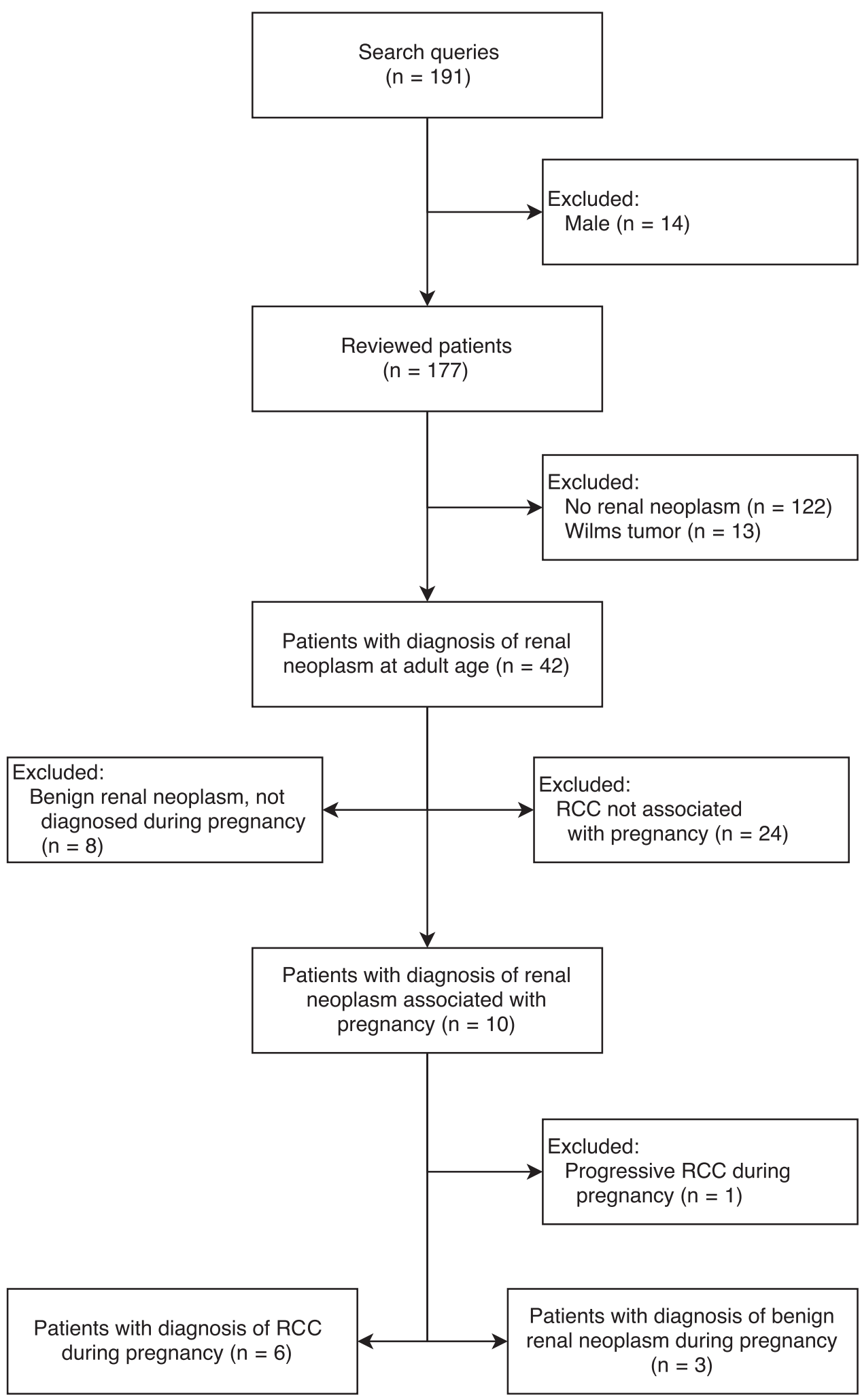

Abbreviation: $\mathrm{RCC}=$ renal cell carcinoma 


\begin{tabular}{|c|c|c|c|c|c|c|c|c|c|c|c|c|c|c|c|}
\hline \multirow{2}{*}{ 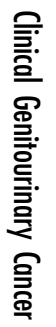 } & able 1 p & \multicolumn{14}{|c|}{ Patients Diagnosed With Renal Neoplasm During Pregnancy or Within the First Month Postpartum } \\
\hline & \multicolumn{15}{|l|}{$\begin{array}{l}\text { Malignant } \\
\text { Renal } \\
\text { Neoplasm }\end{array}$} \\
\hline \multirow[t]{8}{*}{$\begin{array}{l}\text { ב⿳亠े } \\
\text { 言 } \\
\text { 옹 }\end{array}$} & 1 & $7 w$ & $\begin{array}{c}\text { Progressive pain } \\
\text { right lumbar } \\
\text { region }\end{array}$ & G1P0A1 & $\begin{array}{l}\text { Ultrasound scan } \\
\text { of the abdomen, } \\
\text { CT imaging of } \\
\text { the abdomen } \\
\text { and thorax }\end{array}$ & $\begin{array}{c}\text { Partial } \\
\text { nephrectomy } \\
\text { through dorsal } \\
\text { lumbotomy, } \\
\text { 2d after } \\
\text { spontaneous } \\
\text { abortion }\end{array}$ & $\begin{array}{l}\text { Chromophobe } \\
\text { RCC }\end{array}$ & 4 & $8.3 \mathrm{~cm}$ & 7 & pT2aNOMO & $\begin{array}{c}\text { Spontaneous } \\
\text { abortion, GA } \\
7 \mathrm{w}\end{array}$ & $\begin{array}{l}\text { Spontaneous } \\
\text { abortion }\end{array}$ & Sorafenib & $\begin{array}{c}\text { Thoracic } \\
\text { osteoblastic } \\
\text { metastasis after } 7 \\
\text { years, radiotherapy }\end{array}$ \\
\hline & 2 & $7 w 3 d$ & $\begin{array}{c}\text { Acute pain right } \\
\text { hypochondriac } \\
\text { region }\end{array}$ & G3P2A0 & $\begin{array}{c}\text { Ultrasound } \\
\text { imaging of the } \\
\text { abdomen, } \\
\text { transvaginal } \\
\text { ultrasound, MRI } \\
\text { of the kidney and } \\
\text { whole body }\end{array}$ & \begin{tabular}{|c|} 
Radical \\
nephrectomy \\
through Chevron \\
incision at a GA \\
of $7 \mathrm{w} 6 \mathrm{~d}$
\end{tabular} & $\begin{array}{l}\text { Chromophobe } \\
\text { RCC }\end{array}$ & Unknown & $14 \mathrm{~cm}$ & Unknown & pT2bNOMO & \begin{tabular}{|c|} 
Spontaneous \\
missed \\
abortion, GA \\
$9 w$
\end{tabular} & $\begin{array}{l}\text { Spontaneous } \\
\text { abortion }\end{array}$ & None & $\begin{array}{c}\text { No relapse after } 4 \\
\text { months }\end{array}$ \\
\hline & 3 & $17 w$ & $\begin{array}{c}\text { Arterial } \\
\text { hypertension and } \\
\text { decreasing kidney } \\
\text { function }\end{array}$ & G1P0A0 & $\begin{array}{l}\text { Ultrasound } \\
\text { imaging of the } \\
\text { abdomen, MRI } \\
\text { of the kidney }\end{array}$ & \begin{tabular}{|c|} 
Partial \\
nephrectomy with \\
lymphadenectomy \\
through dorsal \\
lumbotomy, at a \\
GA of $18 w$
\end{tabular} & Clear cell RCC & 2 & $6 \mathrm{~cm}$ & 4 & pT1bN2MO & \begin{tabular}{|c|} 
Induced \\
vaginal \\
delivery, GA \\
$36 \mathrm{w} 0 \mathrm{~d}$
\end{tabular} & $\begin{array}{l}\text { Child has tuberous } \\
\text { sclerosis complex }\end{array}$ & None & $\begin{array}{c}\text { Development of } \\
\text { chronic renal failure } \\
\text { with dialysis. Renal } \\
\text { transplantation after } \\
9 \text { years, due to } \\
\text { tuberous sclerosis } \\
\text { complex }\end{array}$ \\
\hline & 4 & $21 w$ & $\begin{array}{c}\text { Acute pain right } \\
\text { lumbar region }\end{array}$ & G1POA0 & $\begin{array}{l}\text { Ultrasound } \\
\text { imaging of the } \\
\text { abdomen, MRI } \\
\text { of the kidney }\end{array}$ & \begin{tabular}{|c|} 
Radical \\
nephrectomy \\
through Chevron \\
incision at a GA \\
of $22 \mathrm{w}$
\end{tabular} & Clear cell RCC & 4 & $14 \mathrm{~cm}$ & 7 & pT2NOMO & \begin{tabular}{|c|} 
Spontaneous \\
vaginal \\
delivery, GA \\
$41 w 3 d$
\end{tabular} & None & None & $\begin{array}{c}\text { No relapse after } 10 \\
\text { years }\end{array}$ \\
\hline & 5 & 28w0d & $\begin{array}{l}\text { Progressive } \\
\text { pain right } \\
\text { lumbar region }\end{array}$ & G2P1A0 & $\begin{array}{l}\text { Ultrasound and } \\
\text { MRI imaging of } \\
\text { 1the abdomen }\end{array}$ & \begin{tabular}{|c|} 
Partial \\
nephrectomy \\
through dorsal \\
lumbotomy, $16 \mathrm{~d}$ \\
after delivery
\end{tabular} & $\begin{array}{l}\text { Chromophobe } \\
\text { RCC }\end{array}$ & 2 & $7.5 \mathrm{~cm}$ & 4 & pT2NOMO & \begin{tabular}{|c|} 
Induced \\
vaginal \\
delivery, GA \\
35w 0d
\end{tabular} & None & None & $\begin{array}{l}\text { No relapse after } \\
5 \text { years }\end{array}$ \\
\hline & 6 & $30 w 6 d$ & $\begin{array}{l}\text { Acute pain left } \\
\text { lumbar and iliac } \\
\text { region }\end{array}$ & G6P3A2 & $\begin{array}{c}\text { Ultrasound } \\
\text { imaging of the } \\
\text { abdomen, MRI } \\
\text { of the kidney. } \\
\text { CT imaging of } \\
\text { the kidney after } \\
\text { delivery }\end{array}$ & $\begin{array}{c}\text { Partial } \\
\text { nephrectomy } \\
\text { through dorsal } \\
\text { lumbotomy } 2 \\
\text { months after } \\
\text { delivery }\end{array}$ & Clear-cell RCC & 2 & $2.8 \mathrm{~cm}$ & 0 & pT1aNOMO & \begin{tabular}{|c|} 
Spontaneous \\
vaginal \\
delivery, GA \\
$37 w 4 d$
\end{tabular} & None & None & $\begin{array}{l}\text { No relapse after } \\
1 \text { year }\end{array}$ \\
\hline & \multicolumn{15}{|l|}{$\begin{array}{l}\text { Benign } \\
\text { Renal } \\
\text { Neoplasm }\end{array}$} \\
\hline & 7 & $16 w 0 d$ & $\begin{array}{l}\text { Acute pain right } \\
\text { lumbar region }\end{array}$ & G1P0A0 & $\begin{array}{l}\text { Ultrasound and } \\
\text { MRI of the } \\
\text { abdomen }\end{array}$ & $\begin{array}{c}\text { Arterial } \\
\text { embolization of } \\
\text { hemorrhaging } \\
\text { pseudoaneurysm } \\
\text { in right kidney }\end{array}$ & \begin{tabular}{|c|} 
Bilateral \\
angiomyolipoma \\
(due to tuberous \\
sclerosis \\
complex)
\end{tabular} & NA & $14.5 \mathrm{~cm}$ & NA & NA & $\begin{array}{c}\text { Termination } \\
\text { of pregnancy, } \\
\text { GA } 17 \mathrm{w} 1 \mathrm{~d}\end{array}$ & $\begin{array}{c}\text { Small retained } \\
\text { placenta, managed } \\
\text { with conservative } \\
\text { therapy. }\end{array}$ & NA & $\begin{array}{l}\text { Medical therapy } \\
\text { with everolimus. } \\
\text { Renal hemorrhage } \\
2 \text { years later }\end{array}$ \\
\hline
\end{tabular}




\begin{tabular}{|c|c|c|}
\hline $\begin{array}{l}\text { 윽 } \\
\text { 3̇ } \\
\text { 음 }\end{array}$ & 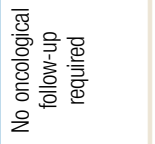 & 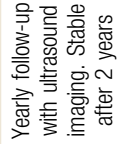 \\
\hline 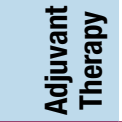 & $\Sigma$ & $\Sigma$ \\
\hline 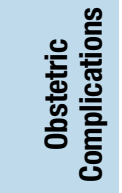 & $\stackrel{0}{\stackrel{0}{2}}$ & $\stackrel{0}{\grave{0}}$ \\
\hline 离 & 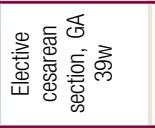 & 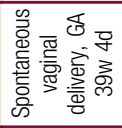 \\
\hline 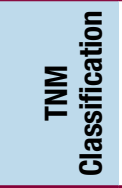 & $\Sigma$ & $\Sigma$ \\
\hline 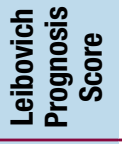 & $\Sigma$ & $\Sigma$ \\
\hline 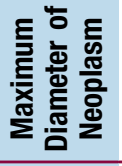 & $\begin{array}{l}E \\
\text { E } \\
\dot{I}\end{array}$ & 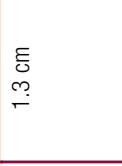 \\
\hline 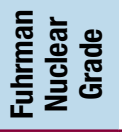 & $\Sigma$ & $\Sigma$ \\
\hline 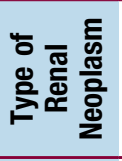 & 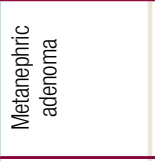 & 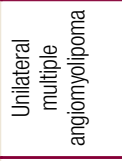 \\
\hline 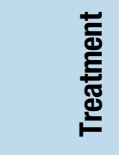 & 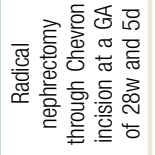 & 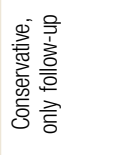 \\
\hline 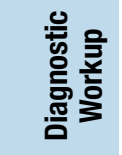 & 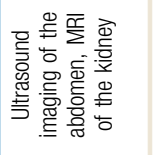 & 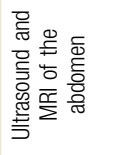 \\
\hline 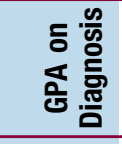 & $\begin{array}{l}\text { 옹 } \\
\text { 읻 }\end{array}$ & 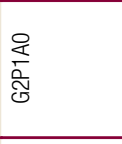 \\
\hline 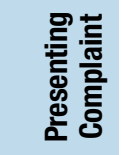 & 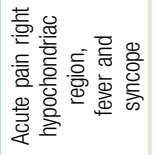 & 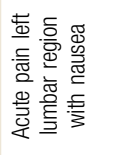 \\
\hline 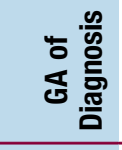 & $\underset{\sim}{\stackrel{\infty}{\sim}}$ & 旁 \\
\hline 힘 & $\infty$ & $\sigma$ \\
\hline
\end{tabular}

development of RCC. ${ }^{14}$ These associations are primordially theoretical and are thought to add only a minimal increase of risk of RCC development during pregnancy.

The renal hyperfiltration hypothesis is suggested as an alternative theory. ${ }^{3}$ Hyperfiltration is known to cause glomerulosclerosis, which is considered a premalignant condition. It increases the susceptibility of nephrons to carcinogens, thus potentially augmenting the risk for RCC development. ${ }^{3}$ Literature about benign renal neoplasms during pregnancy is anecdotal.

Our results show a remarkable preference for atypical RCCs. Half of our patients with RCC (3 out of 6), were eventually diagnosed with a chromophobic type. One patient even developed a very rare metanephric adenoma. It remains, however, unclear how and if pregnancy drives these phenomena.

The presence of syndromic RCC during pregnancy is a second noteworthy element of this case series. TSC is an autosomal dominant genetic disorder. The incidence is estimated at 1 in 10,000 , with renal manifestations in $2 \%$ to $4 \%$ of patients. ${ }^{15}$ One TSC patient in our cohort developed bilateral angiomyolipoma. Typically, TSC affects nearly all organs, causing seizures, mental retardation, skin lesions, and other manifestations. ${ }^{16}$ It is worth mentioning that many TSC patients have latent renal masses and because of a gravid uterus, renal compression occurs, leading to the discovery of these neoplasms.

\section{Management}

Because of the rare incidence of renal neoplasms during pregnancy, evidence-based guidelines are impossible to draft. In our experience, the most important factor in management strategy is the trimester of pregnancy. The balance between potential oncological progress and the obstetric outcome is a delicate one and must be evaluated on an individual basis.

In general, nonobstetric surgery during pregnancy is safe. ${ }^{17}$ However, the timing of surgery should be evaluated by a multidisciplinary team to determine an optimal timing for mother and unborn child.

Recommendations on how to approach renal neoplasms during pregnancy are very scarce. In 1995 Loughlin published a proposal on management of localized renal solid mass neoplasms during pregnancy. ${ }^{18}$ Remarkably, no distinction was made between benign and malignant neoplasms. Loughlin proposed not to postpone surgery during the first trimester because the uterus is small and does not complicate the approach. In the second trimester, there is an option to await surgery until the fetus is viable. If the renal mass is diagnosed during the third trimester, Loughlin advised postponing surgery until after delivery. In late pregnancy, delivery could be induced to minimize therapeutic delay. In our series, induced delivery was performed twice. One was voluntary, because of fear for oncological progression and one was because of declining renal function. Fast-growing retroperitoneal masses could add to the already voluminous abdomen, increasing the risk of ureteral compression, hence, declining the renal function. Although these dated guidelines are not validated, management in our case series still fits within Loughlin's flow chart. Furthermore, the optimal timing of surgery must be reviewed on a case by case basis and should be discussed in a multidisciplinary setting. 


\section{Renal Neoplasm During Pregnancy: A Single Center Experience}

Figure 2 A Selection of Magnetic Resonance Imaging (MRI) Images During Diagnosis: Left Top, Whole Body MRI of Patient 2. Left Bottom, Axial, Patient 7. Right Top, Coronal, Patient 7. Right Middle, Coronal, Patient 2. Right Bottom, Axial, Patient 2. Patient 2: Gestational Age 7 Weeks, 3 Days; Patient 7: Gestational Age 16 Weeks, 0 Days

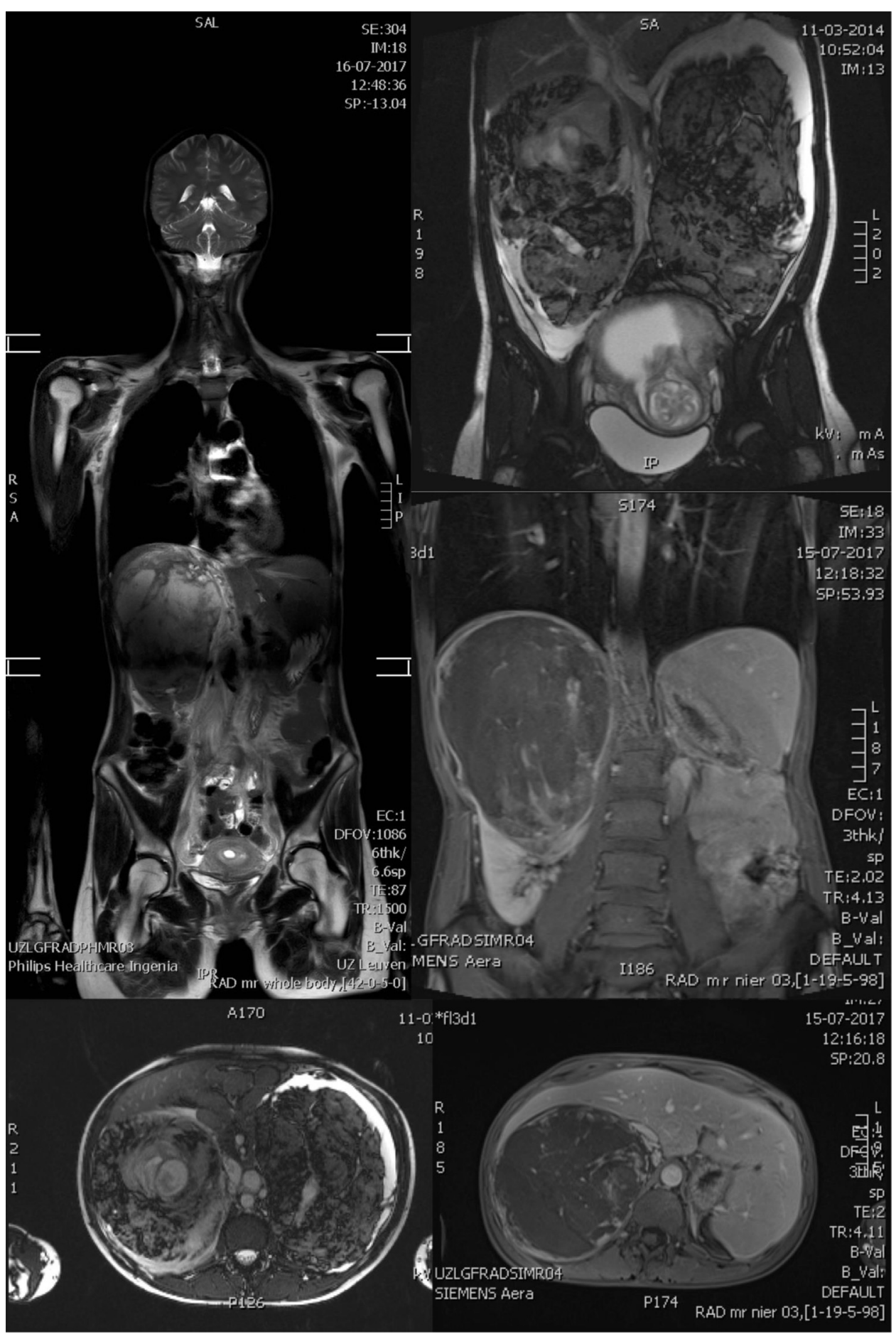

Surgery in pregnancy follows the general trend favoring laparoscopic interventions. Even robot-assisted nephrectomy during pregnancy has been reported. ${ }^{4}$ Evidence concerning the safety of laparoscopy remains, however, inconclusive. ${ }^{17,19}$ Although our center limits laparoscopy to the first trimester because of feasibility, it can be performed at any moment in pregnancy. ${ }^{17,19}$ Notably, the long-term effect on child development after laparoscopic interventions during pregnancy is poorly studied. ${ }^{19}$ Particular points 
of surgical interest include avoidance of perforating the uterus when placing trocars and keeping the intra-abdominal pressure $<12 \mathrm{~mm}$ $\mathrm{Hg}$. This minimizes the effect on functional lung volume and prevents further impairment of venous return. ${ }^{4}$ If the GA exceeds 20 weeks, the surgeon should place the patient in left lateral decubitus to reduce the risk of caval compression by the gravid uterus. If diagnosis is made in a very late stage of pregnancy a cesarean section with synchronous nephrectomy is possible. ${ }^{20}$ Studies on the effect of these surgical interventions on oncological and fetal outcome are lacking.

Patients with a metastasized RCC provide an additional challenge because most systemic chemotherapeutic drugs are contraindicated during the first trimester and could have serious consequences in the second and third trimester. ${ }^{2}$ Management of dispersed renal malignancy during pregnancy reaches beyond the scope of this case series.

Further reporting of these cases and long-term studies are required to propose clear and evidence-based guidelines for these patients.

\section{Ethical Considerations}

The management of renal neoplasms in pregnancy is complex because decisions will not only affect the mother, but also the unborn child. Therefore, these patients should be treated and counseled by a multidisciplinary team. Not only oncological specialists but also obstetricians, pediatricians, psychologists, and genetic specialists should be included and actively involved in the decisionmaking on optimal treatment.

Three actors should be taken into consideration: the mother, the unborn child, and the neoplasm itself. First, most authors conclude that the maternal health is of primary concern. ${ }^{9}$ Not only somatic problems should be addressed; psychological factors are also of great importance. The preferences of the mother are to be carefully counseled and to be respected. They are often the most determining factor in therapy.

Second, the well-being of the unborn child is also of utmost importance. Fetal comorbidities, such as TSC, are major factors in decision-making.

Finally, the neoplasm and the uncertainty of malignancy and progression rate worries the mother as well as the clinician. All of these factors should be taken into consideration to propose a healthy balance between risk of disease progression and the risk of obstetric complications. In our cohort, one patient opted for a TOP because of bilateral renal angiomyolipoma and confirmed fetal tuberous sclerosis at 17 weeks' GA.

Some patients prefer TOP because of fear of oncological progression and desire to optimize their own therapeutic options. It is difficult to underestimate the ethical and emotional burden of this decision. TOP should always be discussed by a multidisciplinary team with both parents and in accordance with local laws.

\section{Conclusion}

Renal masses during pregnancy are an extraordinary rare entity, forming a unique diagnostic, ethical, and therapeutic challenge.
We present a case series of 9 patients who had a diagnosis of renal neoplasm during or within the first month after pregnancy. This single-center cohort constitutes a significant portion of all cases traceable in literature, thus suggesting a severe under-reporting.

General awareness of nonobstetric pathology during pregnancy is important to minimize diagnostic delay. Abdominal ultrasound imaging is the recommended first diagnostic tool and should be complemented with MRI. A CNB could add to the correct diagnosis. Therapeutic options are predominantly determined according to the trimester of pregnancy. Whereas a conservative approach is observed in the third trimester, radical and partial nephrectomies are feasible in second and first trimester with good obstetric and oncological outcomes. This cohort lets us wonder if atypical chromophobic RCCs and syndromic malignancies are more prevalent during pregnancy. Further reporting and long-term studies are required to obtain clear knowledge concerning these rare cases.

\section{Disclosure}

The authors have stated that they have no conflicts of interest.

\section{References}

1. Khaled H, Lahloubi NA, Rashad N. Review on renal cell carcinoma and pregnancy: a challenging situation. J Adv Res 2016; 7:575-80.

2. Boere I, Lok C, Vandenbroucke T, Amant F. Cancer in pregnancy. Curr Opin Oncol 2017; 29:328-34

3. Boussios S, Pavlidis N. Renal cell carcinoma in pregnancy: a rare coexistence. Clin Transl Oncol 2014; 16:122-7.

4. Ramirez D, Maurice MJ, Seager C, Haber GP. Robotic partial nephrectomy during pregnancy: case report and special considerations. Urology 2016; 92 : $1-5$.

5. Ghanney EC, Cavallo JA, Levin MA, et al. Renal cell carcinoma with inferior vena cava thrombus extending to the right atrium diagnosed during pregnancy. Ther Adv Urol 2017; 9:155-9.

6. Scavuzzo A, Santana Rios Z, Diaz-Gomez C, et al. Renal cell carcinoma in pregnant woman with horseshoe kidney. Urol Case Rep 2017; 13:58-60.

7. Binbay M, Yuruk E, Ucpinar B, Binbay Z, Colakerol A, Muslumanoglu AY. Laparoscopic partial nephrectomy for renal-cell carcinoma during pregnancy. J Endourol Case Rep 2016; 2:18-20.

8. Prameela R, Sasirekha R. Ruptured renal cell carcinoma in pregnancy: a rare case presentation. Int I Reprod Contracept Obstet Gynecol 2016; 5:1677-9.

9. Koren G, Carey N, Gagnon R, Maxwell C, Nulman I, Senikas V. Cancer chemotherapy and pregnancy. J Obstet Gynaecol Can 2013; 35:263-78.

10. Johns Putra LG, Minor TX, Bolton DM, Appu S, Dowling CR, Neerhut GJ. Improved assessment of renal lesions in pregnancy with magnetic resonance imaging. Urology 2009; 74:535-9.

11. Ljungberg B, Bensalah $\mathrm{K}$, Canfield $\mathrm{S}$, et al. EAU guidelines on renal cell carcinoma: 2014 update. Eur Urol 2015; 67:913-24.

12. American College of Obstetricians and Gynecologists' Committee on Obstetric Practice. Committee Opinion No. 656: guidelines for diagnostic imaging during pregnancy and lactation. Obstet Gynecol 2016; 127:e75-80.

13. Patel HD, Pierorazio PM. Small renal mass - to biopsy or not? The role of biopsy in evaluation. Eur Urol Focus 2016; 2:154-5.

14. Guan HB, Wu OJ, Gong TT. Parity and kidney cancer risk: evidence from epidemiologic studies. Cancer Epidemiol Biomarkers Prev 2013; 22:2345-53.

15. Yang P, Cornejo KM, Sadow PM, et al. Renal cell carcinoma in tuberous sclerosis complex. Am I Surg Pathol 2014; 38:895-909.

16. Isaacs H. Perinatal (fetal and neonatal) tuberous sclerosis: a review. Am J Perinatol 2009; 26:755-60

17. Balinskaite V, Bottle A, Sodhi V, et al. The risk of adverse pregnancy outcomes following nonobstetric surgery during pregnancy. Ann Surg 2017; 266:260-6.

18. Loughlin KR. The management of urological malignancies during pregnancy. $\mathrm{Br} J$ Urol 1995; 76:639-44.

19. Pearl J, Price R, Richardson W, Fanelli R. Guidelines for diagnosis, treatment, and use of laparoscopy for surgical problems during pregnancy. Surg Endosc 2011; 25: 3479-92.

20. Kobayashi T, Fukuzawa S, Miura K, et al. A case of renal cell carcinoma during pregnancy: simultaneous cesarean section and radical nephrectomy. J Urol 2000; 163:1515-6. 